\title{
On the suitability of regional climate models for reconstructing climatologies
}

\author{
Francisco J. Tapiador ${ }^{\mathrm{a}, *}$, Carlos F. Angelis ${ }^{\mathrm{b}}$, Nicolas Viltard ${ }^{\mathrm{c}}$, \\ Fernando Cuartero ${ }^{\mathrm{d}}$, Manuel de Castro ${ }^{\mathrm{a}}$ \\ a Department of Environmental Sciences, University of Castilla-La Mancha (UCLM), Spain \\ b Centro de Previsão de Tempo e Estudos Climáticos (CPTEC), INPE, Brazil \\ c ETP-CNRS-UVSQ France \\ d Department of Computing Systems, University of Castilla-La Mancha (UCLM), Spain
}

\section{A R T I C L E I N F O}

\section{Article history:}

Received 24 March 2011

Received in revised form 2 May 2011

Accepted 4 May 2011

Available online $\mathrm{xxxx}$

\section{Keywords:}

Regional climate models

Climatologies

Reanalysis

\begin{abstract}
A B S T R A C T
This paper discusses the potential of Regional Climate Models (RCMs) as reanalysis tools by presenting a reconstruction of the European climate using several RCMs with diverse physical parameterizations. The use of RCMs is intended to increase the spatial resolution of the analysis provided by Global Models through dynamic downscaling. At the same time, the use of several models allows us to characterize the uncertainties, as these can be estimated from the spread of the ensemble. When the RCMs are nested in reanalyses instead of in a Global Model it is possible to create climatologies of unprecedented robustness for variables such as temperature, precipitation, wind speed, and humidity, among others. While these climatologies are subject to further improvement as methods and computing power evolve, they point the way forward to the development of atmospheric information products suitable for a variety of studies including education, agriculture, renewable energies and climate change research, biogeography, insurance, risk assessment, hydrology, and regional planning.
\end{abstract}

(c) 2011 Elsevier B.V. All rights reserved.

\section{Introduction}

Present-day climatologies of temperature, precipitation or wind speed have long been used for a variety of applications spanning from agriculture to hydrological planning or insurance. Thus for instance, weather derivatives and weather risk models generated from climate information have emerged as a multidisciplinary field in the energy and insurance sectors (Troccoli et al., 2010). In renewable resources research, the use of climatologies is useful to confirm the optimum location for a solar installation, the establishment of a wind farm, and to dimension hydropower plants (Tapiador, 2009). In hydrological planning (Zappa et al., 2010), it is important to know the seasonal distribution of precipitation and the return periods of

\footnotetext{
* Corresponding author.

E-mail addresses: francisco.tapiador@uclm.es (F.J. Tapiador), angelis@cptec.inpe.br (C.F. Angelis), nicolas.viltard@cetp.ipsl.fr (N. Viltard), fernando.cuartero@uclm.es (F. Cuartero), manuel.castro@uclm.es (M. de Castro).
}

extreme events such as floods. Regarding agriculture, climatologies help farmers to adapt to dry spells and hydric stress mitigating their effects by using crops that are appropriate to the site and by planning ahead. Climate change research also requires precise climatologies as a validation source since a necessary-but by no means sufficient-condition of model performance is the ability to correctly simulate present climate.

Traditionally, climatologies of for instance precipitation were crafted using observations from meteorological stations. These are still considered as the ground truth in spite of known limitations, such as cross-calibration difficulties, observational biases due to wind or evaporation, instrumental errors such as rusty buckets or human misreadings, to name but a few. One possible flaw in the use of observatory data remains the fact that stations only provide pointwise estimates and that these may not adequately represent the spatial variability of local weather. The uncertainties due to the approximation of an areal estimate using point measurements are highly dependent on the network density (Villarini et al., 2008). In the case of precipitation, discrepancies are seldom negligible even at decameter 
range. Interpolation techniques used to generate gridded estimates only worsen the problem, as no matter how sophisticated, these techniques introduce artifacts into the observations (Krajewski, 1987). In the case of solid precipitation, the situation is aggravated due to, for instance, hail being highly localized in space and in time, which makes estimates strongly dependent on the density of the observation network (Sánchez et al., 2009a; Sánchez et al., 2009b; Tuovinen et al., 2009).

With the advent of satellite technology, more homogeneous and comprehensive data became available. Satellites provide areal estimates that represent the mean value of the variable within the instantaneous field of view (IFOV) of the sensor. The use of a single, continuously calibrated instrument contributes to the homogeneity of the records and the inter-calibration of several satellites and the fractional filling of the IFOV present known difficulties (Kummerow, 1998). The retrieval problem, i.e. calculating the actual value of the meteorological parameter from the measured radiances, however, is a mathematically illposed problem; and therefore satellite estimates are sometimes regarded as less direct than observatory data. Although at first controversial for climatologists, this point seemed minor when balanced against the obvious advantages of having quantitative, repeated and objective estimates over both land and sea and, crucially, with the potential of the future reprocessing level-1 data (raw radiances as measured by the sensor) using improved algorithms. Satellite derived climatologies such as those from the TRMM satellite for precipitation and latent heat (Tao et al., 2001) are now widely regarded as fundamental for climate research.

A leap forward in improving our knowledge of climate was the parallel development of reanalysis techniques. Reanalyses embed observational records using data assimilation methods into a physical model. The best-guess (background forecast) created by the model is a representation of the atmospheric state that is the most consistent with observations, albeit that these may have a different weight in the final product. Thus, mean sea level pressure from reanalyses depends strongly on observations, whereas precipitation is a product of the model. Also, depending on data availability in time, reanalyses may be using a varying combination of datasets (weather stations, aircrafts, satellites, etc.) also with a different density of observations for each instrument. Reanalyses such as NCEP's (Kalnay et al., 1996), ERA40 (Uppala et al., 2005), JRA-25 (Onogi et al., 2007) or MERRA (Bosilovich, 2009) provide spatial and temporal homogenous data that amalgamates all the available observations through a physically-consistent process.

A bonus of reanalysis is the ability to estimate derived field such as evapotranspiration, soil moisture, or shortwave radiation that lack comprehensive observations. Besides, reanalyses are fully tridimensional, thus permitting investigating for instance the genesis of weather systems or the role of columnar water vapor in the radiative forcing. The data quality and the moderate spatial resolution of reanalyses (T159 for ERA40, roughly equivalent to $125 \mathrm{~km}$ ) make them useful to conduct climate change studies at scales of hundreds of kilometers and to characterize large scale climatologies.

\section{Regional climate models}

Reanalyses are less useful for climate studies at scales below hundreds of kilometers where local conditions such as topography and land use greatly affect meteorological processes. The final output from a reanalysis represents the average values for the grid point of the model, but depending on the variable quite dissimilar values may coexist within this grid point. The problems associated with coarse grids are particularly acute for patchy variables such as runoff or precipitation (Pedersen et al., 2010), which are likely to be unevenly distributed in a square often larger than $100 \times 100 \mathrm{~km}$ (Larsen et al., 2010).

Regional climate models are physically-based downscaling tools designed to tackle this problem. The RCM physics (dynamics, thermodynamics) and the numerical methods are the same as those in a GCM. The differences are the grid size (from 10 to $75 \mathrm{~km}$ ) and hence smaller time steps, and the limited area of operation, which receives initial and boundary conditions from a parent GCM in a procedure known as oneway nesting (Giorgi et al., 1990). Yet the single improvement of using a RCM does not solve the problem of obtaining better estimates, as there are relevant physical processes at finer resolutions, including cloud and precipitation microphysics, surface processes and turbulence.

The results of a RCM heavily rely on the parameterizations used for still unresolved processes (and unlikely to be ever fully modeled: eddy viscosity is relevant even at centimeter scale and propagates nonlinearly across scales).

Models with different parameterizations yield different results. Physical Ensemble techniques are used to face this problem. The rationale is to run several RCMs with different parameterizations for the unresolved physical processes, using sensible values within uncertainty limits. The mean value of the ensemble is considered an adequate representation of the actual climate while the dispersion of the ensemble reflects the uncertainties that arise from several parameterizations.

\section{The climate as described by RCMs}

The outputs from the RCMs for present-climate conditions are able to be directly translated into climatologies providing the models are nested on reanalysis. While it is known that reanalysis outputs are not the truth, it can be argued that they represent the best available estimate of the climate given our current knowledge of the climate system. A note of caution is however required. As with other climatologies such as those that are satellite-based, the appropriateness of the results for a specific application has to be carefully analyzed, as errors may be large depending on the variable under consideration (Hulme and New, 1997).

In this paper, we present one such exercise, a new reconstruction of the European climate using an ensemble of several independent RCMs with diverse physical parameterizations, numerical methods and modeling strategies. We built climatologies for the 1961-2000 period using the ENSEMBLES project database (van der Linden and Mitchell, 2009). Apart from other products, this project generated a present-climate database from reanalysis data (ERA-40) which is suitable to derive climatologies in Europe. ERA-40 is a well known and robust database that was created integrating observations through assimilation techniques into the IFS CY23r4 model. All the ENSEMBLES data used in this paper are publicly available for download in this web site: http://ensemblesrt3.dmi.dk. 
The European climate as described by the combination of RCMs in the ENSEMBLES project is consistent with that derived from traditional methods. The outputs from the models have been extensively cross-compared with observations (Kostopoulou et al., 2009; Sánchez-Gómez et al., 2009; Lorenz and Jacob, 2010) and have obtained consistent results. The biases of the several RCMs outputs are known and have already been characterized (Christensen et al., 2008); precipitation being the largest and therefore the one that merits most attention here. The scope of this contribution is to qualitatively illustrate the consistency and usefulness of RCMs for deriving climatologies.
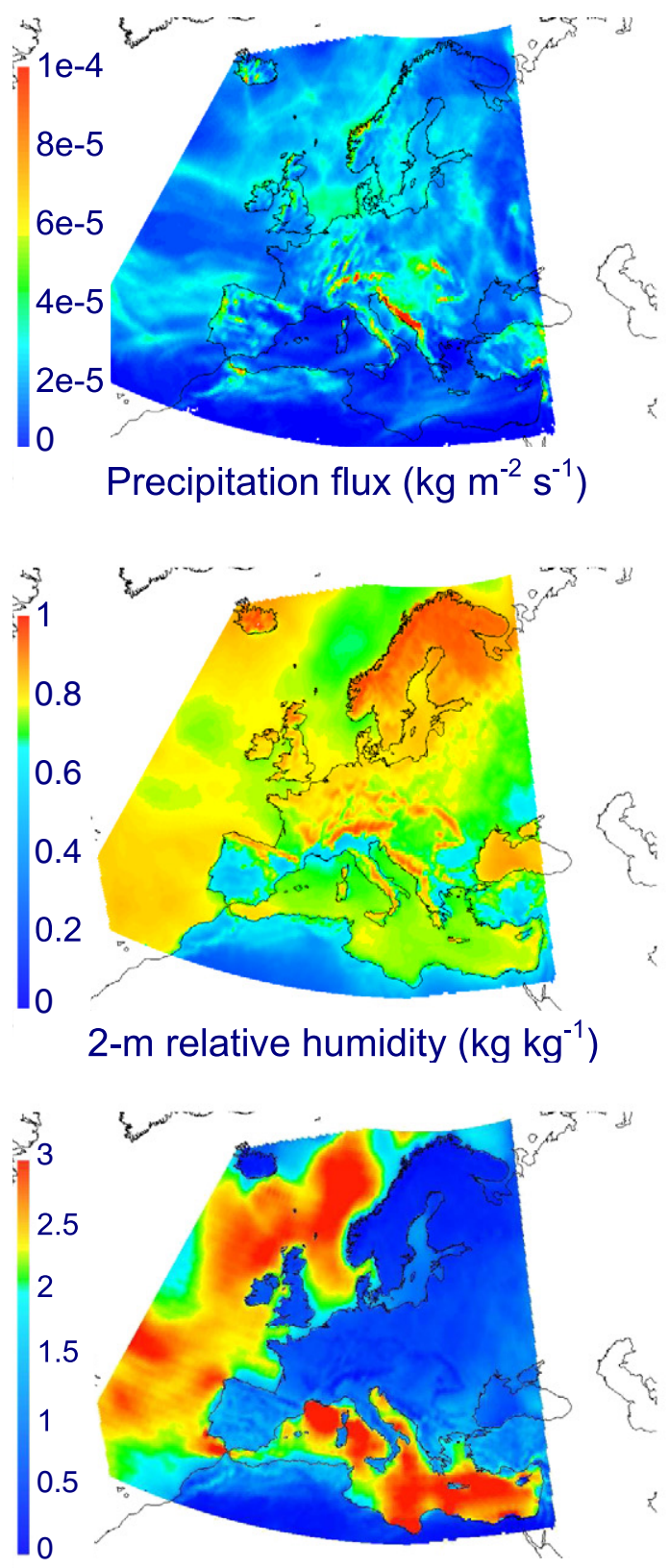

Evapotranspiration $\left(\mathrm{mm} \mathrm{day}^{-1}\right)$
Fig. 1 shows a sample of model output for a single month over the geographical domain used here. Among the many variables of potential climatological interest, precipitation still remains a challenge (Tapiador, 2010). The agreement reanalysis observations for other variables are naturally better, not only because of the lower spatial variability of their fields, but also because some variables such as temperature are an input of the reanalysis. Also, precipitation is highly sensitive to many parameterizations (Khain et al., 2011; Aghakouchak et al., 2010). Modeled precipitation depends at least on cloud microphysics (Shen et al., 2010; Martins et al., 2010), 3D temperature
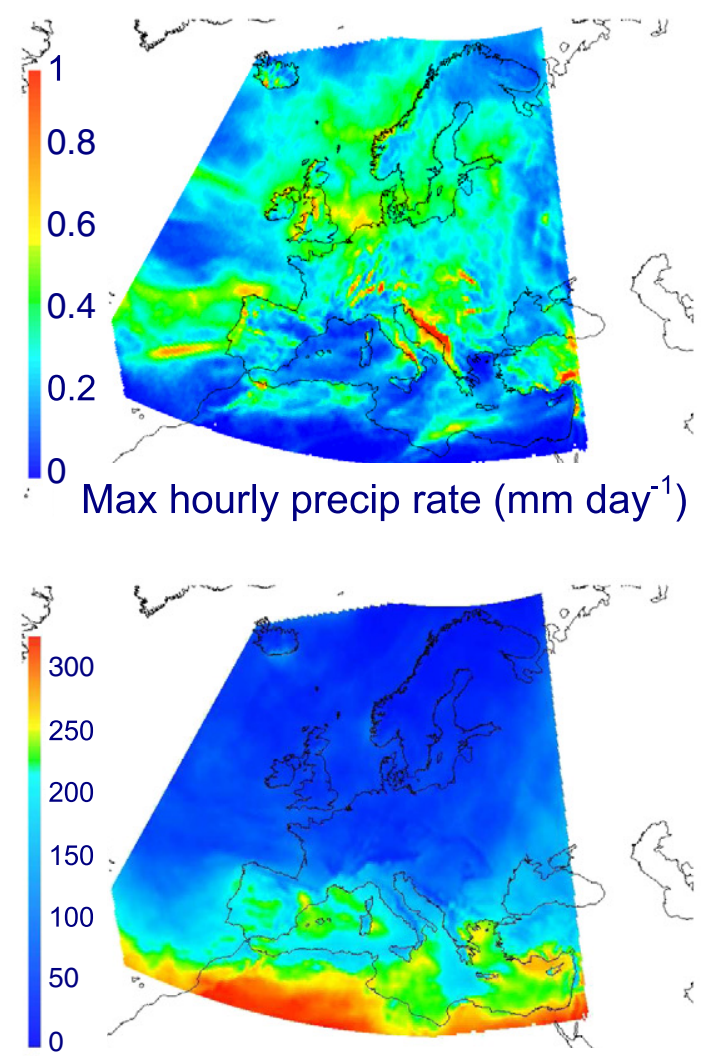

Downward SW radiation $\left(\mathrm{W} \mathrm{m}^{-2}\right)$

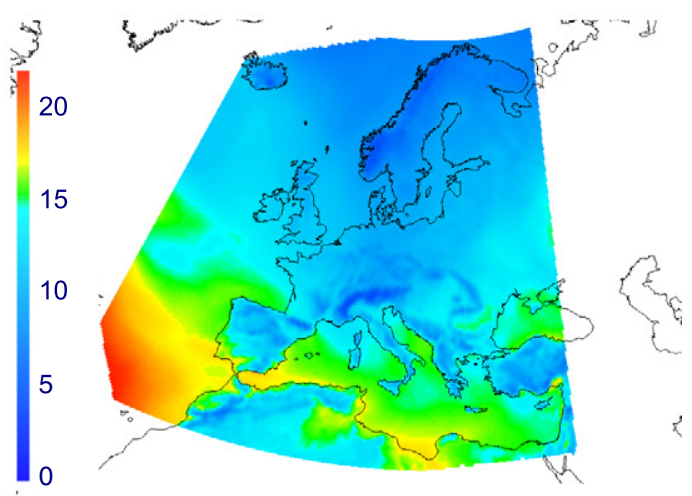

Column water vapor $\left(\mathrm{kg} \mathrm{m}^{-2}\right)$

Fig. 1. RCMs sample outputs for precipitation flux, maximum hourly precipitation, 2 m relative humidity, downward short-wave radiation, evapotranspiration and column water vapor content. Data from ENSEMBLES project database. 
structure, evaporation, water recycling in the soil, irrigation (Lobell et al., 2009) and agricultural practices (Osborne et al., 2009), CAPE, availability of condensation nuclei, and orography. Gross errors and unexpected results are common and large uncertainties still exists in solid precipitation modeling (López et al., 2004; García-Ortega et al., 2005; García-Ortega et al., 2006; García-Ortega et al., in press; Sánchez et al., 2008; Sánchez et al., 2009c), which is not surprising given the difficulties in measuring this phase. Thus, the first precipitation results from ERA40 had to be corrected to account for weaknesses of the humidity scheme utilized in the assimilation system that generated excessive precipitation in the tropics after 1991 (Troccoli and Kållberg, 2004). RCMs that do not take this effect into account may suffer severe difficulties in those regions.

The inherent difficulties in precipitation modeling have prompted the use of precipitation as a tough test for numerical model performance. The rationale is that since precipitation is one of the most difficult variables to get right, if the precipitation field is realistic then the model is probably doing a good job overall. An additional and equally strong reason to prefer using precipitation as a yardstick for model performance is that reanalyses such as ERA-40 do not treat precipitation as a diagnostic variable, i.e. precipitation is not assimilated into the model. Rather, it is a forecasted quantity arising from the simulation, which makes precipitation from observations and from RCMs outputs independent and therefore comparable. Therein, and also to illustrate what might be considered as the worse-case scenario arising in the creation of reliable climatologies from RCMs, we have chosen to focus on precipitation. As we will illustrate next, the results are good enough to consider the RCM outputs as a good estimate of real precipitation. Comparisons of other variables such as temperature give even better performances (Lorenz and Jacob, 2010).

Fig. 2 compares the precipitation outputs of the ENSEMBLES and PRUDENCE (Déqué et al., 2007) projects with three observational datasets: CRU (New et al., 1999), GPCC (Beck et al., 2004) and CPC (Chen et al., 2002). CRU and GPCC are station-based datasets, whereas CPC also includes satellite retrievals. Within an overall consistency, it is noticeable that differences are apparent even for gauge-only gridded data: GPCC and CRU differ only in screening procedures and interpolation techniques, and GPCC even includes CRU data, so one would expect a nearly perfect match between both climatologies. This is not the case, however, as there are clear local differences even for seasonal aggregations. The comparison with the gauge-satellite CPC merged product also shows obvious discrepancies with both CRU and GPCC, suggesting that point-to-point comparison is not a suitable metric, at least for precipitation. Given the differences for precipitation reference data shown in Fig. 2, it is advisable to treat the model comparisons with caution.

Notwithstanding those difficulties, Fig. 2 shows that the RCMs in the PRUDENCE and ENSEMBLES projects compare well with all the observational datasets in terms of capturing the location of maxima and minima and in the spatial patterns, albeit differences may be large locally especially in mountain areas. In this case, it is not clear if one should deem as more credible those sparsely located remote stations in contrasted terrain or the consistent view of the RCMs. Interestingly, the differences are lower in the Alps than in other mountain ranges such as the Pyrenees, which may be indicative of dif- ferences in the quality and density of stations in different places. It is widely recognized that the Alps have a superb, well calibrated and well maintained network one can trust in, but that is not the case in other areas where stations have been historically sparser and less well maintained.

Comparison between ENSEMBLES and PRUDENCE precipitation climatologies in Fig. 2 gives a glimpse on the effects of improved spatial resolution ( $25 \mathrm{~km}$ over $50 \mathrm{~km}$ ) on the precipitation fields. The definition of the precipitation field is obviously better for ENSEMBLES, which clearly shows the orographic effects. ENSEMBLES data also benefits from the fact that the RCMs are nested on reanalysis, and not in GCMs as PRUDENCE RCMs are. This fact is secondary when dealing with climatological mean, but it has to be remembered that there is a fundamental distinction in nesting the RCM into a GCM or into reanalysis. If nested on GCM boundary conditions (as done in the PRUDENCE project) the result can only be treated statistically, i.e., in a climatological sense, and the results reflect the previous limitations of the parent GCM. Nesting on reanalysis and forcing the RCM at real time intervals is different and generates dynamically-downscaled, observationally-consistent climatologies that might even be compared with weather observations. ENSEMBLES time is not synthetic, 30-day months time as in PRUDENCE, but calendar time. The results, however, may look similar when data is aggregated, as Fig. 2 reveals.

Fig. 3 shows the consistency of the estimates for a randomlyselected point (workplace of the corresponding author, Toledo, Spain). The standard boxplots gather the statistics from 480 estimates of monthly precipitation $(12 \times 40$ years $)$ given by eleven RCMs, and compare them with the ensemble mean and equivalent CRU data. The agreement in the annual mean is noticeable and well within the dispersion of the reference database. The figure also illustrates the benefits of the physical ensemble approach: the individual dispersion of the RCMs is reduced by the linear combination of the RCMs, and the resulting ensemble mean is closer to the validation data than any of the models (except METNO, although it exhibits larger dispersion). Statistically, the RCM combination is equivalent to multiplying the sample of 480 single-model monthly data by the number of models, so the uncertainty is reduced and the mean converges faster towards the central value.

Stronger estimates of precipitation and temperature (Fig. 4, bottom) allow us to create better derived climatologies. The ability of calculating a coherent winter vs. summer precipitation climatology (Fig. 4, top) is useful in itself for agriculture, biogeography or regional planning, been also an important factor in regionalizing climates. The biases in measuring winter precipitation are large due to frozen precipitation, gales, or turbulence, and are also different from those in summer, so the reanalysis RCMs nesting approach increases the homogeneity of this important indicator over station-only derived calculations.

Classical climatologies (precipitation and temperature) and those derived climatologies are suitable for many applications, including educational purposes. Old billboard maps depicting the climate of Europe are common across the schools of the continent, but most of them lack the detail that RCMs can provide. Series of digital maps such as those presented here can be inexpensively produced with the data of the ENSEMBLE archive using a Geographical Information System (GIS), which then can be disseminated though the internet. 

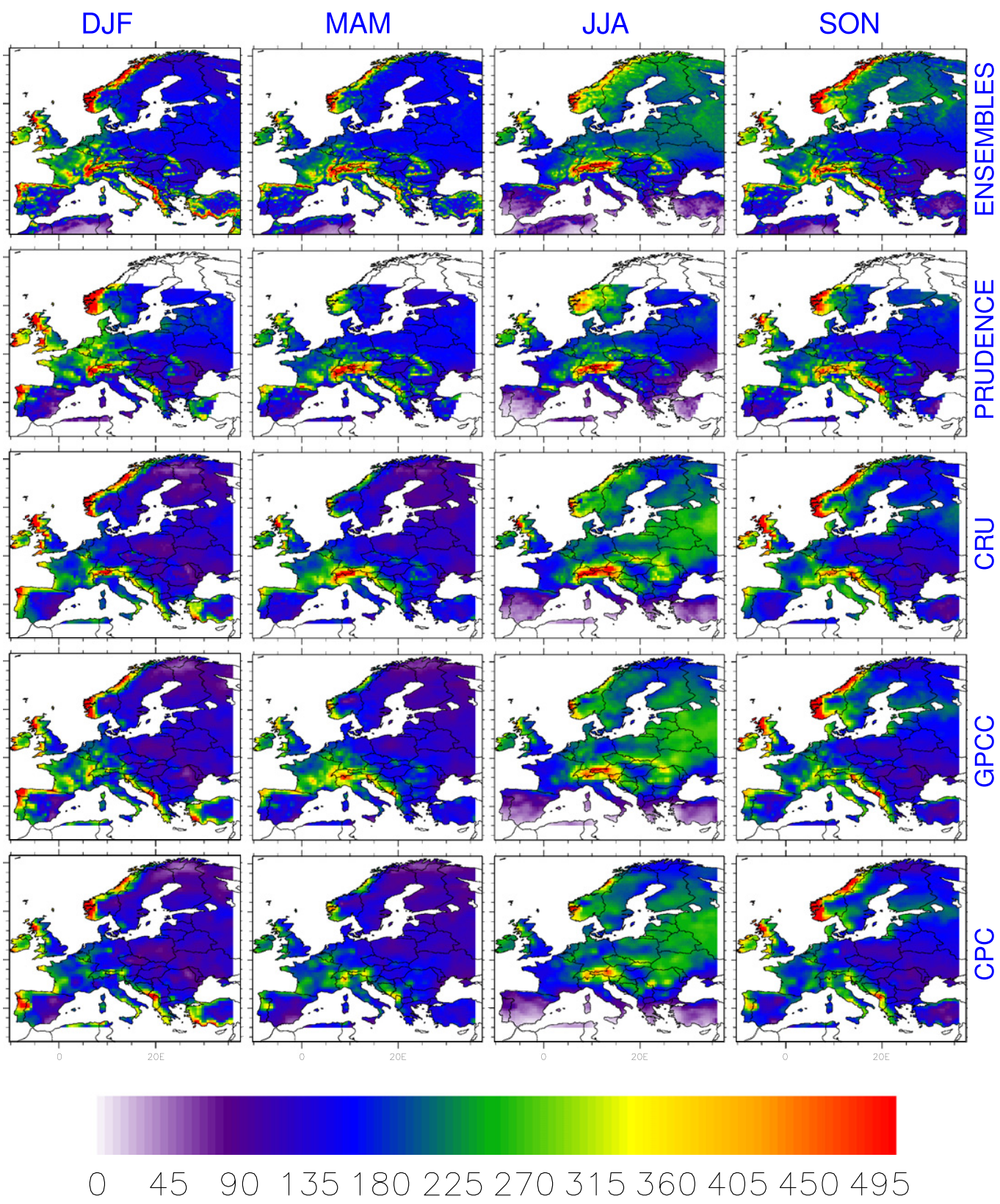

Fig. 2. A comparison of seasonal precipitation climatologies (1961-2000) derived from ten RCMs nested on reanalysis (ENSEMBLES project data, $25 \mathrm{~km}$ grid) compared with ten RCMs forced with GCMs (PRUDENCE project, $50 \mathrm{~km}$ grid), and three observational databases at $50 \mathrm{~km}$ resolution: CRU rain gauge data, GPCC rain gauge data, and CPC rain gauge and satellite-merged data. In spite of the overall agreement, there are local differences even for observational databases (CRU, GPCC and CPC), especially over mountain ranges.

\section{Derived climatologies}

One of the typical uses of climatologies is to classify climates for diverse applications such as biogeographical analyses. Climate classifications have also been used to analyze the changes in the climate signal in SRES scenarios ((Castro et al., 2007), drawing on PRUDENCE project data) as the procedure reduces the dimensionality of the data into a few classes corresponding with those climates relevant for life. Here, Fig. 5 (left) shows three climate classifications using output from the ENSEMBLE project. It is instructive to compare the standard climate classi- fication proposed by Koppen in 1930 with more objectives methods such as K-means or isodata algorithms. Thus, K-means for 5 and 10 output classes were calculated using the same data used in the Koppen scheme (as implemented in (Lohmann et al., 1993)), namely the seasonal monthly means of temperature and precipitation, the winter/summer precipitation ratio, and the maxima and minima for annual, winter and summer precipitation and temperature, totaling 16 variables. Comparing land use, NDVI (Fig. 5, right) with Koppen's and Kmeans climates, K-means classifications seem more realistic than Koppen's. This is not a surprise since Koppen's focus was in 


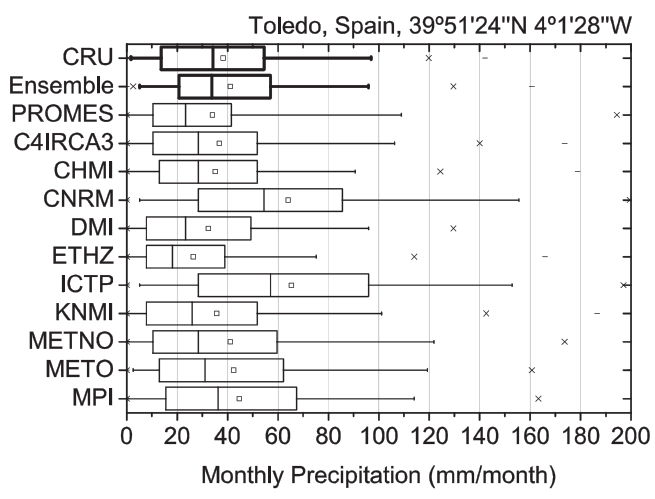

Fig. 3. Boxplots of monthly precipitation 1961-2000 in Toledo, Spain, for 11 RCMs, the ensemble mean of the models, and CRU data. The boxes in the boxplots mark the lower, median and upper quartiles; the small square represents the mean; and the whiskers indicate the 5th and 95th percentiles. The agreement between observations and the RCMs ensemble mean is significant. providing a global scheme rather than a regional view. His scheme used aggregated data and a decision tree algorithm to derive what in fact was a manual classification based upon vegetation types. On contrast, objective classifications permit an automatic approach that classifies the data in the ndimensional configuration space given by input data, with no a priori indication of what the resulting climates should be. Even so, the overall agreement with the vegetation types (land use and NDVI plots) is patent in Fig. 5, portraying the link between climate, human activities and natural life. More complicated objective classifications using disaggregated data (monthly or even daily data), more variables (wind speed, frozen precipitation) or a different number of classes are easy to generate from the RCMs outputs.

Regarding applications, one typical application of climate models is mapping offshore wind resources. Climatologies of wind speed benefit from RCMs modeling as station data is almost absent over sea. Satellites can estimate wind speed over sea, though: the sea surface gives different responses depending

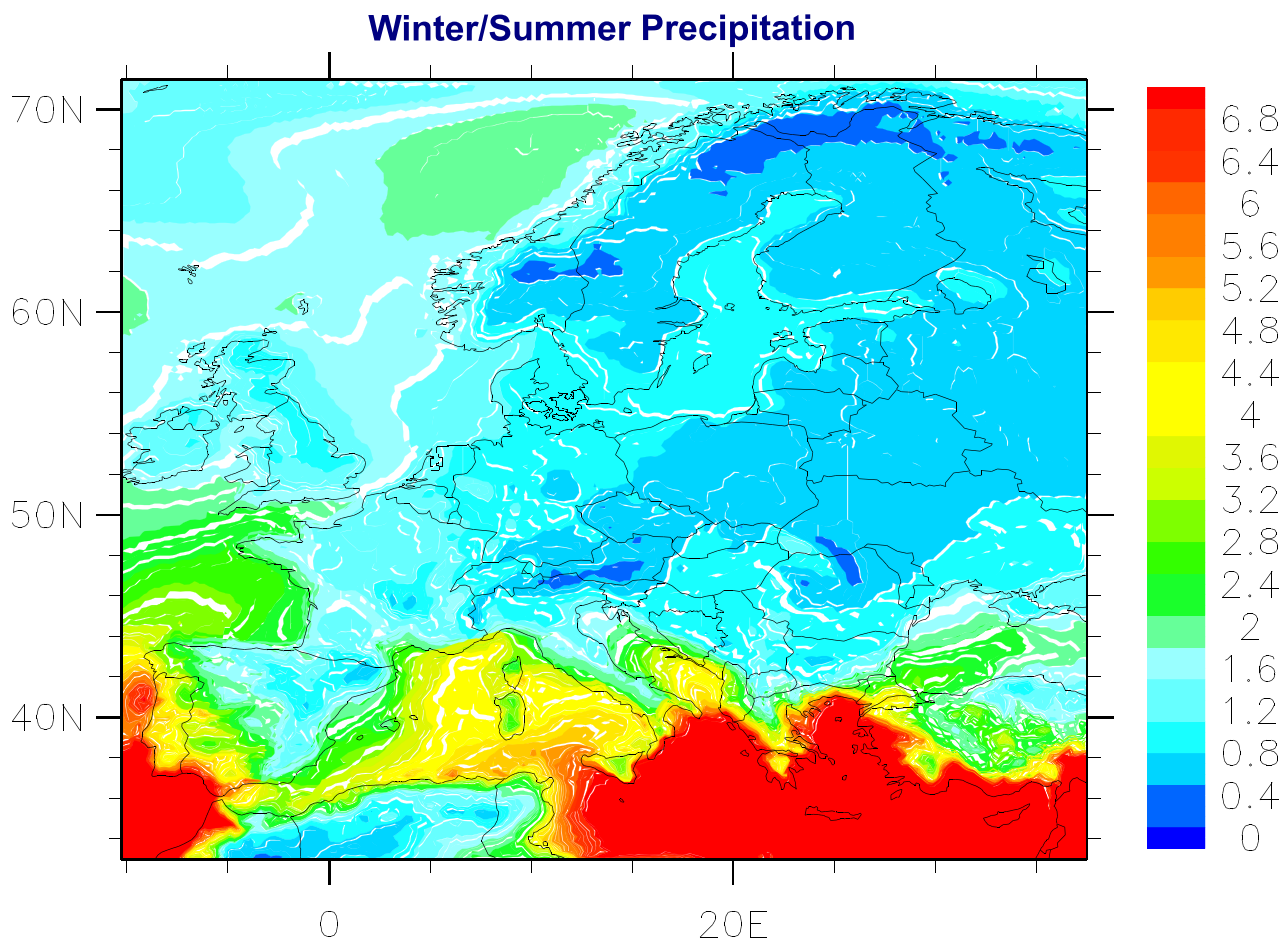

\section{2-m Temperature}

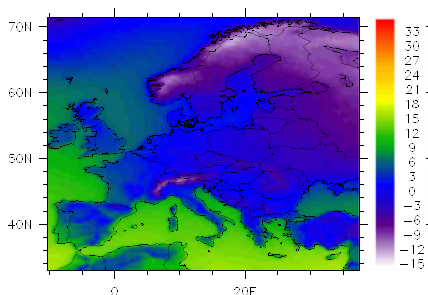

DJF

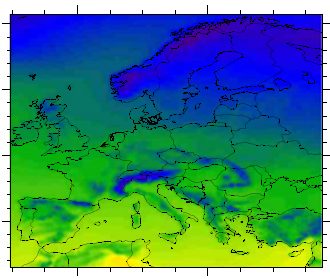

MAM

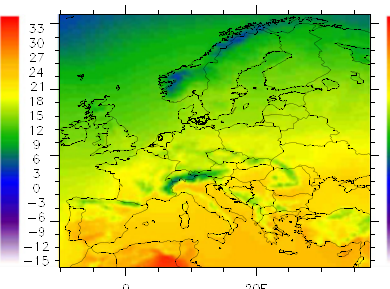

JJA

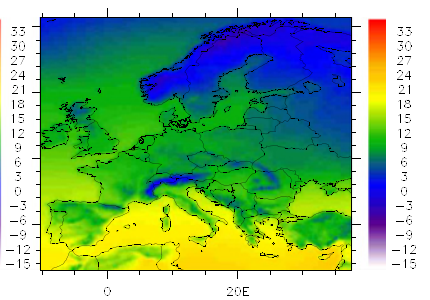

SON

Fig. 4. Winter vs summer precipitation ratio (top) and seasonal climatologies for temperature as described by the mean of 11 RCMs. The winter/summer ratio clearly outlines the North-South gradient and the Mediterranean climate. 

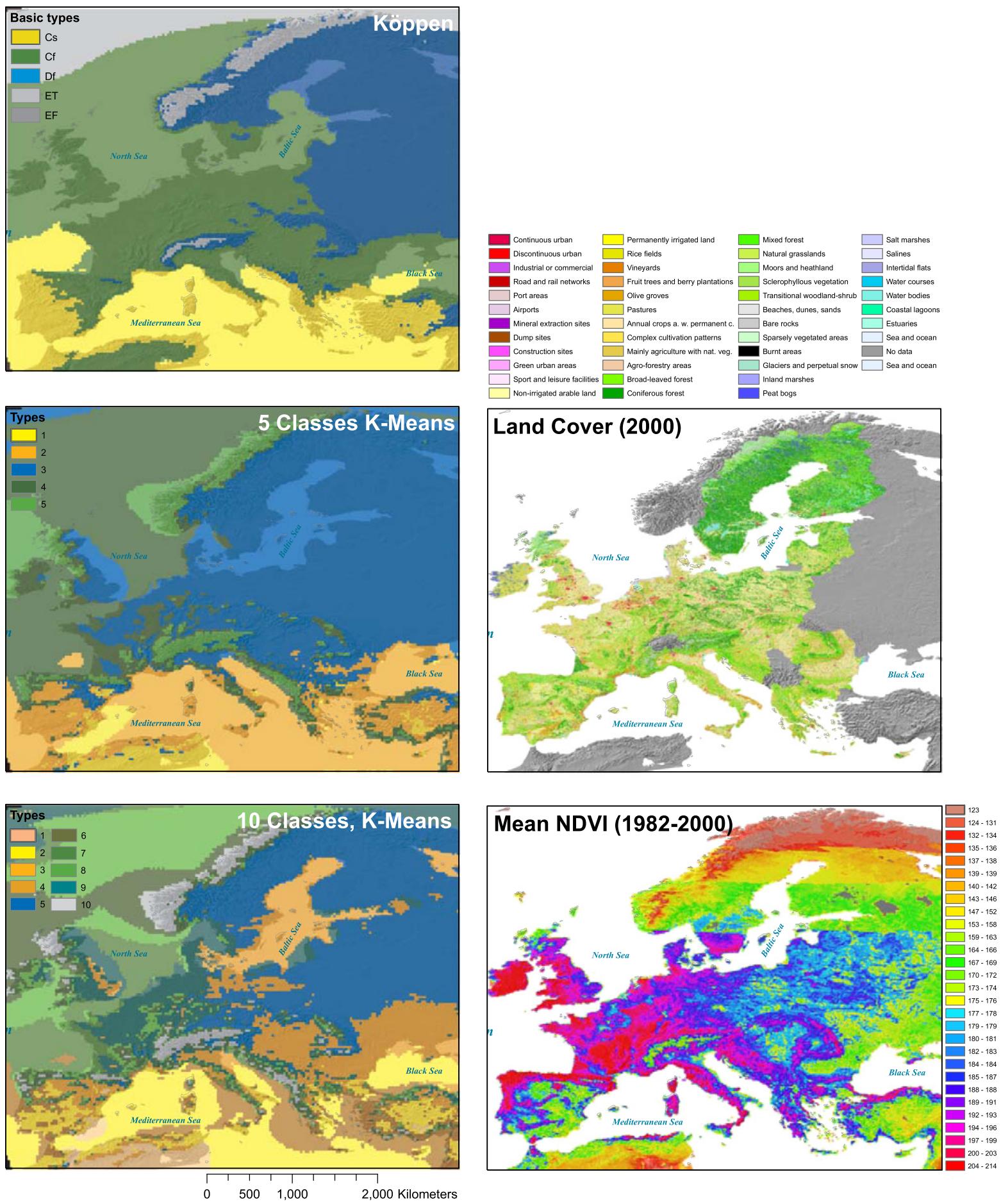

Fig. 5. Koppen classical climate classification derived from an ensemble of eleven RCMs (top, left) and two objective classifications using the K-means algorithm, for 5 classes (middle, left) and 10 classes (bottom, left). The input data for classifying algorithms is the same in the three cases. For comparison, the land use in 2000 (CORINE project, middle right), and the mean NDVI scaled from 0 to 255 for the 1982-2000 period (except 1994, bottom right) are also shown. NDVI data was derived from the NOAA-AVHRR sensor. The objective classifications seem more realistic than Koppen's when compared with vegetation strength, also providing improved definition of local climates as the number of classes increases.

on the wind stress and this fact permits an estimate of the actual surface wind speed under some reasonable assumptions. The main interest for wind energy applications is the wind speed at blade height and not at surface level, so empirical relationships exist to derive the variation of the estimated surface wind speed with height. However, this method is less accurate than directly 
using the dynamical core of the model to that end. Also, the length of satellite records is small, and, crucially, does not permit short-term forecasting that may help operations. Satellites are nonetheless useful, as reanalyses assimilate satellite retrievals of surface wind estimates.

The climatology from an ensemble of RCMs (Fig. 6) illustrates a possible wind climatology derived from RCMs, here the 'mean monthly wind speed'. Depending on applications, the third power of the maximum daily wind speed, or the wind statistics derived from fitting the data to a parametric distribution may be more suitable (Klinger et al., 2006). What is relevant here is that the map illustrates the way the high resolution of RCMs output allows a better discrimination of the wind patterns in Europe. As this map represents a mean wind

Mean 2-m Wind Speed m/s

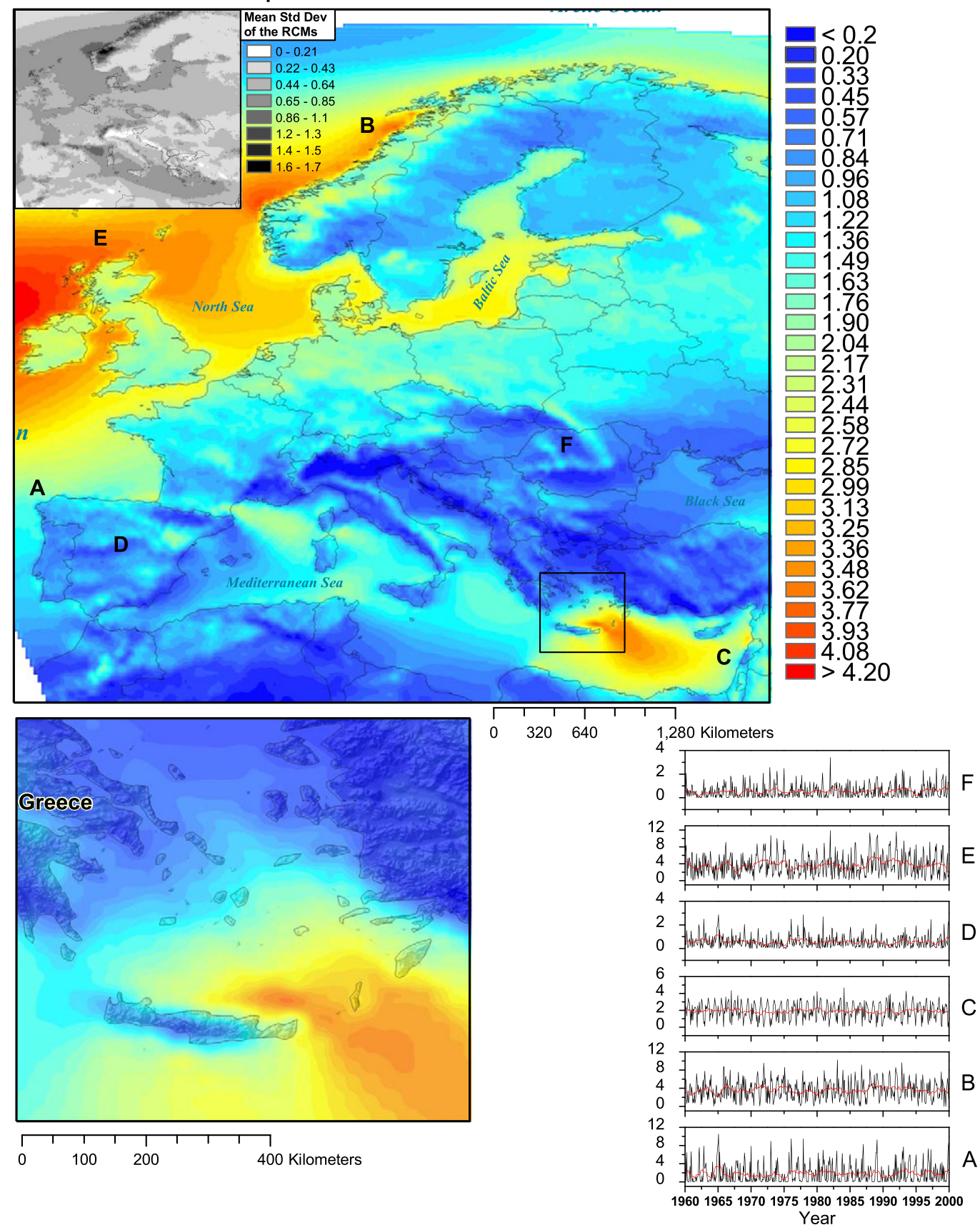

Fig. 6. 2-meter wind speed monthly average as described by the ensemble mean of eleven RCMs. The mean standard deviation of the RCMs is also shown, indicating little spread. Time series corresponds with the mean monthly average for the six locations indicated on the main map. The inset picture zooms the effect of Crete island on the Etesian winds. 
over day, night and across seasons, constant winds appear more marked in the map than possibly stronger seasonal winds. The trajectories of the Westerlies are apparent, as they are the differences due to topography. The relatively calm South face of the Pyrenees vividly contrasts with the North, windier side. The differences with the rest of the Mediterranean and the channeling of the flow (Kotroni et al., 2001) are apparent in the strait off north Crete. The deflection effects on the Etesian winds are noticeable (Fig. 6, bottom): Crete affects mainly the South-Eastern part of the Aegean Sea where in the islands of Karpathos and Kasos, and the North-Eastern part of Crete, where gale or even strong gale winds (8-9 Beaufort scale) are reported quite often during the summertime period of the Etesian winds. Other well-known wind systems within the Mediterranean such as the Mistral wind off Southern France also appear in the simulations. The Bora wind, however, is nearly absent, probably due to the aggregation effect mentioned above.

The ensemble approach permits us to compare the confidence boundaries of the climatologies. In the case of wind, the spread of the RCMs in terms of the mean standard deviation of the models (Fig. 6, inset) shows that models differ more on the Norwegian coast, with little differences (below $0.85 \mathrm{~m} / \mathrm{s}$ ) elsewhere. Agreement among RCMs using different parameterizations and numerical schemes builds confidence, in that the RCM mean is a good statistic of the distribution of the real variable.

\section{Conclusions}

Ensembles of RCMs offer a dynamically-consistent way of integrating sparse observations from a variety of sources through downscaling of reanalyses. RCM climatologies present some differences when compared with classical, observationally-based climatologies, including that they provide more homogenous estimates over both land and sea, the ability to generate 3D products and better spatial resolution. Contrary to observations, RCM outputs cannot be considered as final. Improved parameterizations, better models for key processes such as convection, and increased computing power will certainly make future RCMs better than those available today. New reanalyses with those models will progressively lessen the gap between data and mode outputs by extracting the most from the observations.

Given the 5 years life span of quasi-realistic models in climate science (Muller and Von Storch, 2004), the European climate we describe here will surely be different in less than a decade. Nonetheless, it will probably differ little given the observed performances of the RCMs. Given the current state of the art, it is safe to say that climatologies from RCMs are the best available consistent estimates of the climate, and that they can be used in several applications, including education.

Conceding that the models are not perfect, maps such as Fig. 6 are more informative than coarser isoline maps based on sparse ground data that suffer from many other problems; the paucity of the base information to name but one. Moreover, climatologies are often used to compare different locations, and not to provide the actual value of a parameter in a place. In this case, the mismatch between data sources is less critical than the homogeneity of the estimates.
The European interest in RCM modeling presented here is not isolated. The North American Regional Climate Change Assessment Program (NARCCAP) can be seen as the counterpart of European RCM efforts, also nesting RCMs in 1979-2004 NCEP/DOE-Reanalysis 2as part of validation tasks (Mearns, 2009). Providing comparative links between both sides of the Atlantic is fertile research ground (Rowell, 2009), and comparing improved modeling strategies such as NARCCAP spectral nudging may benefit the creation of better climatologies from RCMs everywhere. Given the potential of this physical approach to climate analysis, it is not surprising that coordination activities for RCM modelers are starting to emerge. Thus, the World Climate Research Program promotes a COordinated Regional climate Downscaling EXperiment (CORDEX). Among other goals, CORDEX aims to coordinate a range of RCM simulations forced by ERA-Interim to provide a benchmark framework for model evaluation and assessment. Also, the Arctic System Reanalysis (ASR) will provide high resolution description in space (10-20 km) and time ( $3 \mathrm{~h}$ ) of the atmosphere-sea ice-land surface system of the Arctic since 1957 (Bromwich et al., 2010). Apart from the intrinsic importance of RCMs for investigating global warming, the present-day climatologies that can be derived from those large projects will help us to add pieces to the incomplete jigsaw of the global climate.

The path followed to construct climatologies from pointwise to area estimates, and then to homogenous, gapless 3D fields seems a logical way forward to understand the earth climate. The forthcoming use of nonhydrostatic RCMs, assimilation of longer series of satellite data, advances in parallel computing, steady progress in parameterizations, and coupling with biochemical cycles, aerosol effects, and societal impacts will all contribute to our knowledge of the planetary climate and to the development of atmospheric applications to serve society.

\section{Appendix A. Derived analyses}

The potential climatologies that can be derived from the RCMs outputs are endless. Just to illustrate a case of intermediate complexity, precipitation data can be used to analyze the relative contribution of the annual, intraanual and interannual processes to the precipitation. Applying wavelet analysis to the RCMs ensemble of monthly precipitation estimates results in climatologies of relative contributions of each process. Fig. 7 illustrates the results of such comparison. As explained in the figure caption, the maps are the result of analyzing 36,000 series of monthly precipitation derived from an ensemble of eleven RCMs. For each series (as that marked as (a) in Fig. 7), the wavelet power spectrum is derived using a Morlet wavelet. The resulting plot (b) indicates the relative contribution of undulatory (not necessarily cyclic) components. Areas where the interannual component is stronger than the annual component are potential candidates to stronger teleconnection patterns with multi-year planetary perturbations. In those areas where the annual cycle is also relevant, coupled dynamics are likely to appear. The fine grain of these maps helps us to identify isolated spots whose character is shown by local factors such as orography or land use.

Regional analyses of finer resolution sea level pressure fields are another potential application from RCMs outputs. The improved resolution of RCMs over reanalysis enhances the ability to analyze mesoscale features such as those related to 

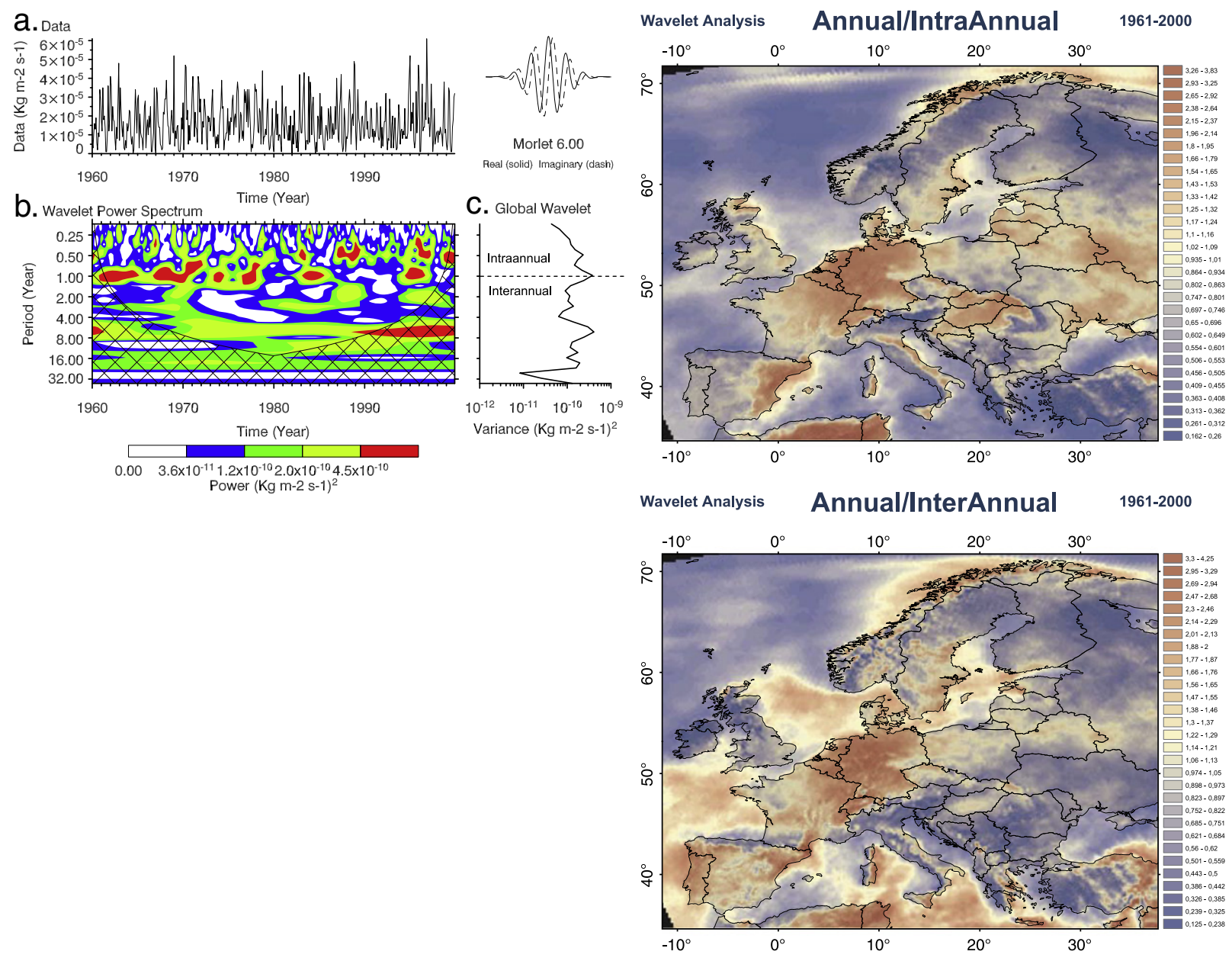

Wavelet Analysis IntraAnnual/InterAnnual 1961-2000

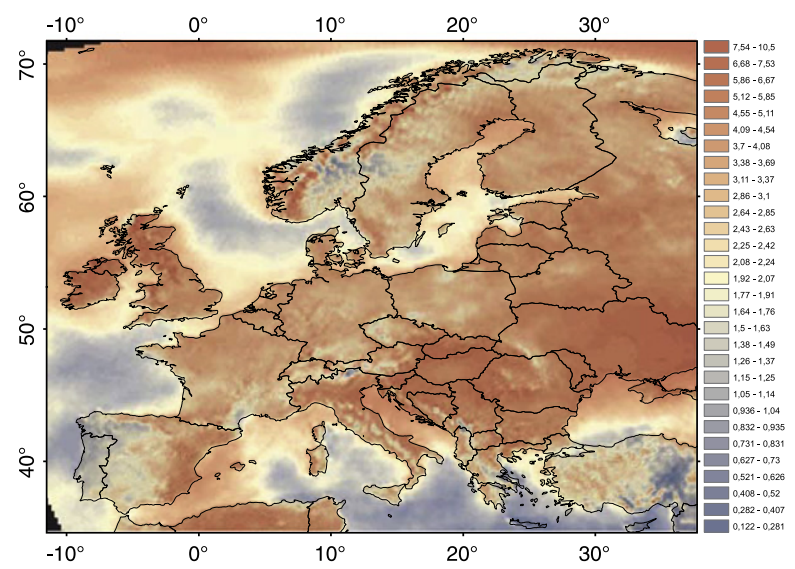

Fig. 7. (left) Wavelet power spectra (Torrence and Compo, 1998) of the mean monthly precipitation field of eleven RCMs for a single location (Toledo City, Spain, $30^{\circ} 51^{\prime} 24^{\prime \prime} \mathrm{N} 4^{\circ} 1^{\prime} 28^{\prime \prime} \mathrm{W}$ ). The upper part (a) depicts the original time series of precipitation. The wavelet power spectra (b) portray the cyclic components of the series, illustrating the relative contributions of the annual, intra-annual and inter-annual frequencies at each point in time. The global wavelet (c) is the sum across time for each frequency. Note the signature of drought in the late 80 s and early 90s. (right) Relative contributions of the annual and intra-annual frequencies to the overall variability of the precipitation in Europe. Each grid point on the map indicates the ratio between the annual and intra-annual components of a global wavelet such as the one in the left. The figure provides information on where teleconnection patterns with multi-year planetary perturbations such as ENSO or $\mathrm{NAO}$ are likely to be relevant in the European precipitation cycles. 

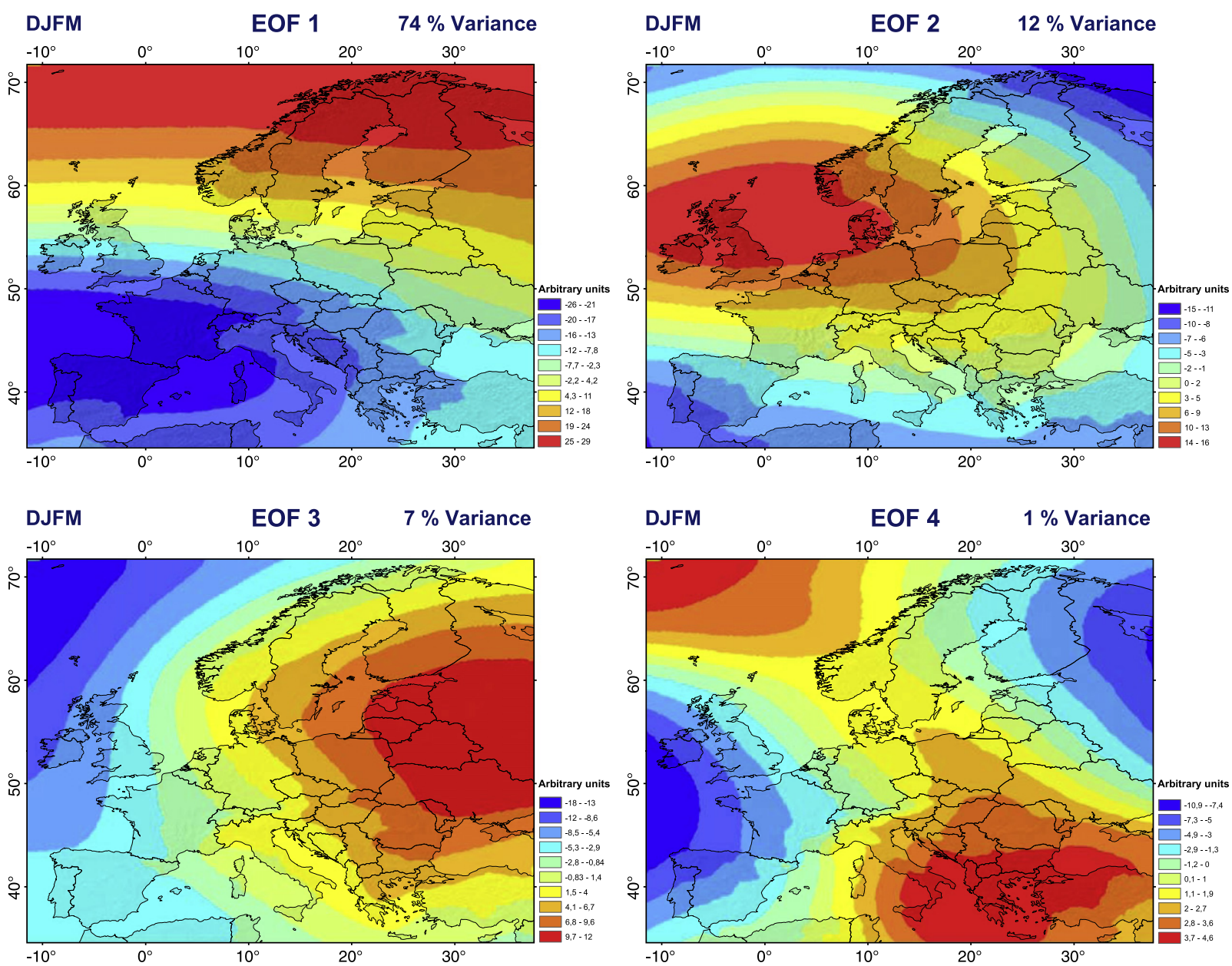

Fig. 8. Empirical Orthogonal Functions (EOFs) resulting from Principal Components Analysis (PCA) of the sea level pressure anomaly in the ENSEMBLES domain as described by an ensemble of eleven RCMs (25 km resolution). The plots indicate the overall variance explained by each EOF. The sign and value of the EOFs are conventionally arbitrary. The Northern Atlantic Oscillation (NAO) is revealed as the latitudinal dipole shown in the first EOF.

the Northern Hemisphere Arctic Mode (NAM). Fig. 8 presents a Principal Component Analysis (PCA) of the sea level pressure anomaly as described by an ensemble of ten RCMs at $25 \mathrm{~km}$ resolution. The four EOF look like previous analyses using coarser resolution data, with the first EOF showing a window of what is commonly identified as the North Atlantic Oscillation (NAO, (Hurrell et al., 2001)), a latitudinal dipole whose effects include governing the succession of droughts in the Iberian Peninsula. The effects of improving resolution are noticeable in for example the Alps and the Carpathians, where the isolines curve following the mountain ranges. The variance explained by each component differs from coarser resolution databases. The first two EOFs capture $74 \%$ and $12 \%$ of the series variance, compared with $55 \%$ and $14 \%$ only using reanalysis data. It is known that the captured variance depend on the domain and not only on spatial resolution, so the results here are not directly comparable with hemispheric analyses. Nonetheless, the larger separation of the EOFs is also a good signal of enhanced performances. As in the case of other variables, the ability to have regular data of surface level pressure, even over the oceans, contributes to increase the statistical strength of the calculations because sample size increases notably.

\section{Acknowledgements}

This work has been funded through projects CGL201020787-C02-01, CGL2010-20787-C02-02, CENIT PROMETEO (MICCIN), and PPII10-0162-554 (JCCM). The ENSEMBLES data used in this work was funded by the EU FP6 Integrated Project ENSEMBLES (Contract number 505539) whose support is gratefully acknowledged. PRUDENCE project (EVK2-CT-2001-00132), CRU, GPCC, GPCP, and CMAP data providers are also gratefully acknowledged. Land use map corresponds with the 2007 European Environment Agency CLC2000. NDVI data was obtained from NASA Goddard DAAC ftp site.

\section{References}

Aghakouchak, A., Habib, E., Bardossy, A., 2010. A comparison of three remotely sensed rainfall ensemble generators, Atmospheric Research, Volume 98, Issues 2-4. International Conference on Nucleation and Atmospheric Aerosols (Part 1)-ICNAA 2009, November-December 20100169-8095, pp. 387-399. doi:10.1016/j.atmosres.2010.07.016. 
Beck, C., Grieser, J., Rudolf, B., 2004. A new monthly precipitation climatology for the global land areas for the period 1951 to 2000. German Weather Service Climate Status Rep, Offenbach, Germany, pp. 181-190.

Bosilovich, M., 2009. NASA's Modern Era Retrospective-Analysis for Research and Applications (MERRA). Presentation to the Department of Earth and Atmospheric Sciences, Purdue University, Sept 24, 2009.

Bromwich, D.H., Kuo, Y.-H., Serreze, M., Walsh, J., Bai, L.-H., Barlage, M., Hines, K., Slater, A., 2010. Arctic system reanalysis: call for community involvement. EOS Transactions AGU. 91 (2), 13. doi:10.1029/2010EO02000.

Castro, M., Gallardo, C., Jylha, K., Tuomenvirta, H., 2007. The use of a climatetype classification for assessing climate change effects in Europe from an ensemble of nine regional climate models. Climate Change 81, 329-341.

Chen, M., Xie, P., Janowiak, J.E., Arkin, P.A., 2002. Global land precipitation: a 50 -yr monthly analysis based on gauge observations. Journal Hydrometeor. 3, 249-266.

Christensen, J.H., Boberg, F., Christensen, O.B., Lucas-Picher, P., 2008. On the need for bias correction of regional climate change projections of temperature and precipitation. Geophysical Research Letters 35 (20), L20709. doi:10.1029/2008GL035694.

Déqué, M., Rowell, D.P., Lüthi, D., Giorgi, F., Christensen, J.H., Rockel, B., Jacob, D., Kjellström, E., Castro, M., van den Hurk, B., 2007. An intercomparison of regional climate simulations for Europe: assessing uncertainties in model projections. Climatic Change 81, 53-70 Supplement 1.

García-Ortega, E., Fita, L., Romero, R., López, L., Ramis, C., Sánchez, J.L., 2005. Numerical simulation and sensitivity study of a severe hailstorm in northeast Spain, Atmospheric Research, Volume83, Issues 2-4, European Conference on Severe Storms 2004-ECSS 2004. European Conference on Severe Storms 2004, February 20070169-8095, pp. 225-241. doi:10.1016/ j.atmosres.2005.08.004.

García-Ortega, E., López, L., Sánchez, J.L., Marcos, J.L., 2006. Microphysical analysis at the cloud edge of a severe hailstorm, Atmospheric Research, Volume 82 , Issues 1-2, 14th International Conference on Clouds and Precipitation-14th ICCP. 14th International Conference on Clouds and Precipitation, November 20060169-8095, pp. 337-349. doi:10.1016/j.atmosres.2006.01.009.

García-Ortega, E., López, L., Sánchez, J.L., 2010. Atmospheric patterns associated with hailstorm days in the Ebro Valley, Spain, Atmospheric Research,2010 Volume 100, Issue 4, June 2011, Pages 401-427, 5th European Conference on Severe Storms.

Giorgi, F., Marinucci, M.R., Visconti, G., 1990. Use of a limited-area model nested in a general-circulation model for regional climate simulation over Europe. Journal of Geophysical Research-Atmospheres 95 (D11), 18413-18431.

Hulme, M., New, M., 1997. Dependence of large-scale precipitation climatologies on temporal and spatial sampling. Journal of Climate 10 (5), 1099-1113.

Hurrell, J.W., Kushnir, Y., Visbeck, M., 2001. The North Atlantic oscillation. Science 291 (5504), 603-605

Kalnay, E., Kanamitsu, M., Kistler, R., Collins, W., Deaven, D., Gandin, L., Iredell, M. Saha, S., White, G., Woollen, J., Zhu, Y., Leetmaa, A., Reynolds, R., Chelliah, M., Ebisuzaki, W., Higgins, W., Janowiak, J., Mo, K.C., Ropelewski, C., Wang, J. Jenne, R., Joseph, D., 1996. The NCEP/NCAR 40-year reanalysis project. Bulletin of the American Meteorological Society 77 (3), 437-471.

Khain, A., Rosenfeld, D., Pokrovsky, A., Blahak, U., Ryzhkov, A., 2011. The role of $\mathrm{CCN}$ in precipitation and hail in a mid-latitude storm as seen in simulations using a spectral (bin) microphysics model in a 2D dynamic frame. Atmospheric Research (ISSN: 0169-8095) 99 (1), 129-146. doi:10.1016/ j.atmosres.2010.09.015 January 2011.

Klinger, B.A., Huang, B., Kirtman, B., Schopf, P., 2006. Monthly climatologies of oceanic friction velocity cubed. Journal of Climate 19 (21), 5700-5708.

Kostopoulou, E., Tolika, K., Tegoulias, I., Giannakopoulos, C., Somot, S., Anagnostopoulou, C., Maheras, P., 2009. Evaluation of a regional climate model using in situ temperature observations over the Balkan Peninsula. Tellus A 61 , 357-370.

Kotroni, V., Lagouvardos, K., Lalas, D., 2001. The effect of the island of Crete on the Etesian winds over the Aegean Sea. Quarterly Journal of the Royal Meteorological Society 127 (576), 1917-1937.

Krajewski, W., 1987. Cokriging radar-rainfall and rain gage data. Journal of Geophysical Research 92 (D8), 9571-9580.

Kummerow, C., 1998. Beamfilling errors in passive microwave rainfall retrievals. Journal of Applied Meteorology 37 (4), 356-370.

Larsen, M.L., Clark, A., Noffke, M., Saltzgaber, G., Steele, A., 2010. Identifying the scaling properties of rainfall accumulation as measured by a rain gauge network. Atmospheric Research (ISSN: 0169-8095) 96 (1), 149-158. doi:10.1016/j.atmosres.2009.12.008 April 2010.

Lobell, D., Bala, G., Mirin, A., Phillips, T., Maxwell, R., Rotman, D., 2009. Regional differences in the influence of irrigation on climate. Journal of Climate 22 (8), 2248-2255.

Lohmann, U., Sausen, R., Bengtsson, L., Cubasch, U., Perlwitz, J., Roeckner, E., 1993. The Koppen climate classification as a diagnostic tool for genera circulation models. Climate Research 3, 177-193.

López, L., García-Ortega, E., Sánchez, J.L., 2004. A short-term forecast model for hail, Atmospheric Research, Volume 83, Issues 2-4, European Conference on
Severe Storms 2004-ECSS 2004. European Conference on Severe Storms 2004, February 20070169-8095, pp. 176-184. doi:10.1016/j.atmosres. 2005.10.014.

Lorenz, P., Jacob, D., 2010. Validation of temperature trends in the ENSEMBLES regional climate model runs driven by ERA40. Climate Research 44, 167-177.

Martins, R.C.G., Machado, L.A.T. Costa, A.A., 2010. Characterization of the microphysics of precipitation over Amazon region using radar and disdrometer data, Atmospheric Research, Volume 96, Issues 2-3. 15th International Conference on Clouds and Precipitation - ICCP 2008, May 20100169-8095, pp. 388-394. doi:10.1016/j.atmosres.2010.01.011.

Mearns, L.O., 2009. Climate Change Assessment Program (NARCCAP). GEWEX/ILEAPS Joint Meeting, Melbourne, Australia. August 25, 2009.

Muller, P., Von Storch, H., 2004. Computer Modelling in Atmospheric and Ocean Sciences. Springer-Verlag.

New, M., Hulme, M., Jones, P., 1999. Representing twentieth century spacetime climate variability. Part I: development of a 1961-90 mean monthly terrestrial climatology. Journal Climate 12, 829-856.

Onogi, K., Tsutsui, J., Koide, H., Sakamoto, M., Kobayashi, S., Hatsushika, H., Matsumoto, T., Yamazaki, N., Kamahori, H., Takaehashi, K., Kadokura, S., Wada, K., Kato, K., Oyama, R., Ose, T., Mannoji, N., Taira, R., 2007. The JRA25 Reanalysis. Journal of the Meteorological Society of Japan 85, 369-432.

Osborne, T. Slingo, J., Lawrence, D., Wheeler, T., 2009. Examining the interaction of growing crops with local climate using a coupled cropclimate model. Journal of Climate 22 (6), 1393-1411.

Pedersen, L., Jensen, N.E., Christensen, L.E., Madsen, H., 2010. Quantification of the spatial variability of rainfall based on a dense network of rain gauges. Atmospheric Research (ISSN: 0169-8095) 95 (4), 441-454. doi:10.1016/ j.atmosres.2009.11.007 March 2010.

Rowell, D.P., 2009. Projected midlatitude continental summer drying: North America versus Europe. Journal of Climate 22 (11), 2813-2833.

Sánchez, J.L., López, L., Bustos, C., Marcos, J.L., García-Ortega, E., 2008. Short-term forecast of thunderstorms in Argentina, Atmospheric Research, Volume 88, Issue 1, April 20080169-8095, pp. 36-45. doi:10.1016/j.atmosres.2007. 09.005 .

Sánchez, J.L., Gil-Robles, B., Dessens, J., Martin, E., López, L., Marcos, J.L., Berthet, C., Fernández, J.T., García-Ortega, E., 2009a. Characterization of hailstone size spectra in hailpad networks in France, Spain, and Argentina. Atmospheric Research 93 (1-3), 641-654.

Sánchez, J.L., Marcos, J.L., Dessens, J., López, L., Bustos, C., García-Ortega, E., 2009b. Assessing sounding-derived parameters as storm predictors in different latitudes, Atmospheric Research, Volume 93, Issues 1-3, 4th European Conference on Severe Storms-4ECSS. 4th European Conference on Severe Storms, July 20090169-8095, pp. 446-456. doi:10.1016/ j.atmosres.2008.11.006.

Sánchez, J.L., Gil-Robles, B., Dessens, J., Martin, E., López, L., Marcos, J.L., Berthet, C., Fernandez, J.T., García-Ortega, E., 2009c. Characterization of hailstone size spectra in hailpad networks in France, Spain, and Argentina, Atmospheric Research, Volume 93, Issues 1-3, 4th European Conference on Severe Storms-4ECSS. 4th European Conference on Severe Storms, July 20090169-8095, pp. 641-654. doi:10.1016/j.atmosres.2008.09.033.

Sánchez-Gómez, E., Somot, S., Déqué, M., 2009. Ability of an ensemble of regional climate models to reproduce weather regimes over EuropeAtlantic during the period 1961-2000. Climate Dynamics 33, 723-736.

Shen, X., Wang, Y., Zhang, N., Li, X., 2010. Roles of large-scale forcing, thermodynamics, and cloud microphysics in tropical precipitation processes. Atmospheric Research (ISSN: 0169-8095) 97 (3), 371-384. doi:10.1016/ j.atmosres.2010.04.014 August 2010

Tao, W.-K., Lang, S., Olson, W.S., Meneghini, R., Yang, S., Simpson, J., Kummerow, C., Smith, E., Halverson, J., 2001. Retrieved vertical profiles of latent heat release using TRMM rainfall products for February 1988. Journal of Applied Meteorology 40 (6), 957-982.

Tapiador, F.J., 2009. Assessment of renewable energy potential through satellite data and numerical models. Energy \& Environmental Science 7 (2), 1142-1161.

Tapiador, F.J., 2010. A joint estimate of the precipitation climate signal in Europe using eight regional models and five observational datasets. Journal of Climate 23 (7), 1719-1738.

Torrence, C., Compo, G.P., 1998. A practical guide to wavelet analysis. Bulletin of the American Meteorological Society 79, 61-78.

Troccoli, A., Kållberg, P., 2004. Precipitation Correction in the ERA-40 Reanalysis. ERA-40 Project Report Series No. 13. ECMWF, Reading, England.

Troccoli, A., Boulahya, M.S., Dutton, J.A., Furlow, J., Gurney, R.J., Harrison, M., 2010. Weather and climate risk management in the energy sector. Bulletin of the American Meteorological Society 785-788. doi:10.1175/ 2010BAMS 2849.1.

Tuovinen, J.P., Punkka, A.-J., Rauhala, J., Hohti, H., Schultz, D.M., 2009. Climatology of Severe Hail in Finland: 1930-2006. Monthly Weather Review 137 (7), 2238-2249.

Uppala, S.M., Kllberg, P.W., Simmons, A.J., Andrae, U., Bechtold, V.D.C., Fiorino, M., Gibson, J.K., Haseler, J., Hernandez, A., Kelly, G.A., Li, X., Onogi, 
K., Saarinen, S., Sokka, N., Allan, R.P., Andersson,, E., Arpe, K., Balmaseda, M.A., Beljaars, A.C.M., Berg, L.V.D., Bidlot, J., Bormann, N., Caires, S., Chevallier, F., Dethof, A., Dragosavac, M., Fisher, M., Fuentes, M., Hagemann, S., Hólm, E., Hoskins, B.J., Isaksen, L., Janssen, P.A.E.M., Jenne, R., Mcnally, A.P., Mahfouf, J.-F., Morcrette, J.-J., Rayner, N.A., Saunders, R.W., Simon, P., Sterl, A., Trenberth, K.E., Untch, A., Vasiljevic, D., Viterbo, P., Woollen, J., 2005. The ERA-40 re-analysis. Quarterly Journal of the Royal Meteorological Society 131 (612), 2961-3012.

van der Linden, P., Mitchell, J.F.B. (Eds.), 2009. ENSEMBLES: climate change and its impacts: summary of research and results from the ENSEMBLES project. Met Office Hadley Centre, FitzRoy Road, Exeter EX1 3PB, UK. 160 pp.

Villarini, G., Mandapaka, P.V., Krajewski, W.F., Moore, R.J., 2008. Rainfall and sampling errors: a rain gauge perspective. Journal of Geophysical Research 113, D11102. doi:10.1029/2007JD009214.

Zappa, M., Jaun, S., Germann, U., Walser, A., Fundel, F., 2010. Super-position of three sources of uncertainties in operational flood forecasting chains, Atmospheric Research2010 Volume 100, Issues 2-3, May 2011, Pages 246-262. Uncertainty Propagation in Advanced Hydro-Meteorological Forecast Systems. 